MATEC Web of Conferences 13, 02033 (2014)

DOI: $10.1051 /$ matecconf/ 20141302033

(C) Owned by the authors, published by EDP Sciences, 2014

\title{
Performance and Emission Characteristics of an IDI Diesel Engine Fuelled Biodiesel (Rubber Seed Oil and Palm Oil Mix) Diesel Blends
}

\author{
Ibrahim K. Adam ${ }^{1, a}$,A. Rashid A. Aziz ${ }^{1}$ and Suzana Yusup ${ }^{2}$ \\ ${ }^{1}$ Universiti Teknologi PETRONAS, Mechanical Department, 3750 Tronoh Perak, Malaysia \\ ${ }^{2}$ Universiti Teknologi PETRONAS, Chemical Department, 3750 Tronoh Perak, Malaysia
}

\begin{abstract}
In this study crude rubber seed oil and palm oil were mixed at 50:50 vol.feedstock's blending methods is motivated by cost reduction and properties enhancement. Biodiesel was produced and thermo physical properties are studied. Blends of B5, B10 and B20 of biodiesel to diesel were prepared. Engine performance (torque, brake specific fuel consumption (BSFC), brake thermal efficiency (BTE)) and emission ( $\mathrm{CO}, \mathrm{NOx}$ and exhaust gas temperature) were evaluated in a 4 cylinder, natural aspirated, indirect injection (IDI) diesel engine. The results indicated that at rated engine speed of $2500 \mathrm{rpm}$ torque obtained were 87, 86, 85.3 and $85 \mathrm{Nm}$ for neat diesel, B5, B10 and B20 respectively. Torque in all blends case yield between 0 to $5 \%$ lower than neat diesel. BTE were $27.58,28.52$, and $26.45 \%$ for B5, B10 and B20 compared to neat diesel $26.99 \%$. At lower blends ratio BSFC was found to be lower and increased proportional to the blends ratio. The $\mathrm{CO}$ emission reduced but the exhaust gas temperature and NOx increased as blends ratio increases.
\end{abstract}

\section{Introduction}

Due to the growth the demand of fossil fuel increased while the production decreases [1]. Thus, attributed towards depletion and environmental pollutions form emission and results in increasing temperature. The change in the global temperature has serious impact on the agriculture production, health and environmental disasters. Pollutants such as $\mathrm{CO}, \mathrm{NOx}, \mathrm{CO}_{2}$ and many volatile organic matters emitted from burning of fossil fuel reduce the air quality around the world.Therefore, alternative energy sources are the most attractive option for fossil fuel replacement. Biodiesel is a liquid fuel produced from different feedstocks such as vegetable oil, either edible or non-edible oil waste, animal fats, and algae. Biodiesel production from refined oil is not feasible due to food threat and high production cost [2]. Thus, inedible vegetable oil has a potential to overcome food threats with the advantage of less sulphur contents, availability, liquid nature and biodegradability [3, 4, 5]. Vegetable oil can be directly used in the diesel engine like Rudolf Diesel that used the Peanut oil first time as the fuel. Consequently, due to high viscosity, incomplete combustion, deposition of particulate matters and lower volatility it cannot work properly like diesel fuel [6, 7]. Ramadhas et al [8] studies

\footnotetext{
${ }^{\text {a } C o r r e s p o n d i n g ~ a u t h o r ~: ~ h i m a k h 80 @ g m a i l . c o m ~}$
} 
the characterization and the effect of using rubber seed oil as fuel in a single cylinder diesel engine. It is observed that $50-80 \%$ blends give better performance. Reksowardojo et al [9] conducted experiment on a single cylinder diesel engine using rubber seed oil biodiesel blend. It is found that, SFC increased while BTE reduced. The CO, total hydrocarbon (THC) and smoke opacity were lower in 5\% blend compared to neat diesel. Ramadhas et al [10] evaluated performance and emissions of rubber seed methyl esters blends in a single cylinder diesel engine. It is observed that the BTE improved, SFC and emissions were reduced by using lower blend ratio.Geo et al [11] studies on improvement of diesel engine performance using dual fuel rubber seed oil and diethyl ester (DEE) as ignition improver. They claimed that BTE improved, smoke opacity; THC and carbon monoxide were reduced. Raheman et al [12] tested soot, performance and emission on a single cylinder diesel engine using biodiesel blends, B10 and B20 obtained from a mixture of mahua and simarouba oils at 50:50 blend ratio with high speed diesel. The results indicated that BSFC and NOx were increased while $\mathrm{BTE}, \mathrm{CO}$ and $\mathrm{HC}$ decreased. Biodiesel characteristics, engine performance and emissions are important for eventual optimization and utilization. Hence, its application in society will reduce the dependent on fossil fuel. However, work on the combination of rubber seed oil and palm oil as the feedstockhas not studied and still is research gap. Thus, an experimental investigation is conducted to evaluate the performance and exhaust emission of rubber seed oil and palm oil biodiesel at 50:50 blend ratio as supplement to neat diesel fuel, B5, B10 and B20 in a fully instrumentindirect injection diesel engine.

\section{Materials}

The crude rubber seed oil was purchased through Kinetics chemicals (M) Sdn. Bhd, the crude palm oil was purchased from Felcra chemicals (M) while the fossil diesel was obtained from a local fuel station. All the reagents and chemical were analytical grade and purchased from the Sigma Aldrich Malaysia.

\subsection{Characterization of fuel properties}

The density of the biodiesel and the blends were analysed by using the Anton Paar DMA 4500M Density Meter, following ASTM D 5002 standard method. Viscosity of the biodiesel and blends were measured using Anton Paar, Lovis 2000 M/ME apparatus, following DIN 53015 and ISO 12058 standard. The low temperature properties such as cloud point referred to ASTM D 2500 and pour point referred to ASTM D 97 were measured by using the CPP 5G's analyzer. Cold filter plugging point was measured by using the FPP 5G's analyzer by following the ASTM D 6371. Oxidation stability was measured by using the 873-CH-9101 Metrohmanalyzer by following the EN 14114 .

Table 1.Biodiesel fuel properties

\begin{tabular}{|l|l|l|l|l|}
\hline Property & Methods & RSPOB & ASTM D 6751 & EN 14214 \\
\hline Densityat $25^{\circ} \mathrm{C} \mathrm{kg} / \mathrm{m}^{3}$ & ASTM D 5002 & 874 & N/A & $860-900$ \\
\hline Viscosityat $\mathrm{mm}^{2} / \mathrm{s}, 40{ }^{\circ} \mathrm{C}$ & ASTM 445 & 4.9 & $1.9-6.0$ & $3.5-5$ \\
\hline Calorific value $(\mathrm{MJ} / \mathrm{kg})$ & & 38.4 & - & - \\
\hline CentaneNumber & ASTM D 613 & 50.19 & $47 \mathrm{~min}$ & $51 \mathrm{~min}$ \\
\hline Oxidationstability (h) & EN14114 & 3.77 & $3 \mathrm{~min}$ & $6 \mathrm{~min}$ \\
\hline Flash Point $\left({ }^{\circ} \mathrm{C}\right)$ & ASTM D 93 & 150 & $93 \mathrm{~min}$ & $120 \mathrm{~min}$ \\
\hline Cloud Point $\left({ }^{\circ} \mathrm{C}\right)$ & ASTM D 2500 & 1 & - & - \\
\hline Pour Point $\left({ }^{\circ} \mathrm{C}\right)$ & ASTM D 97 & 6.5 & - & - \\
\hline Cold FilterPlugging Point $\left({ }^{\circ} \mathrm{C}\right)$ & ASTM D 6371 & 3.8 & - & - \\
\hline Moisture content $(\%)$ & ASTM D 2709 & 0.02 & 0.05 max & 0.05 max \\
\hline Ester Content $(\%)$ & EN 14103 & 98.113 & N/A & 96.6 \\
\hline
\end{tabular}




\subsection{Engine test}

The XLD 418D with bore of $82.5 \mathrm{~mm}$, stroke of $82 \mathrm{~mm}$, compression ratio of 21.5:1, torque of 110 $\mathrm{Nm}$ at $2500 \mathrm{rpm}$, power output of $44 \mathrm{~kW}$ at $4800 \mathrm{rpm}, 4$ strokes, natural aspirated, indirect injection (IDI) diesel engine was used for the present investigation as shown in Fig.1. The engine and dynamometer were controlled by a control panel equipped with data acquisition, logging and sensors. The sensors measured engine speed, torque, lubrication oil pressure and temperature, coolant inlet and outlet temperature, fuel pressure, inlet air temperature and fuel consumption. Vario plus industrial exhaust gas analyzer were used to measure gaseous emission such as carbon monoxide (CO) and nitrogen oxide (NOx). The experiments were conducted in a series of operation condition in full load, at engine speed range from 1000 to $4500 \mathrm{rpm}$ with an interval of 500. During the experiment the engine was allowed to warm up for about 15 minutes. For every fuel change, fuel lines were cleaned with neat diesel and the gas analyser was calibrated.

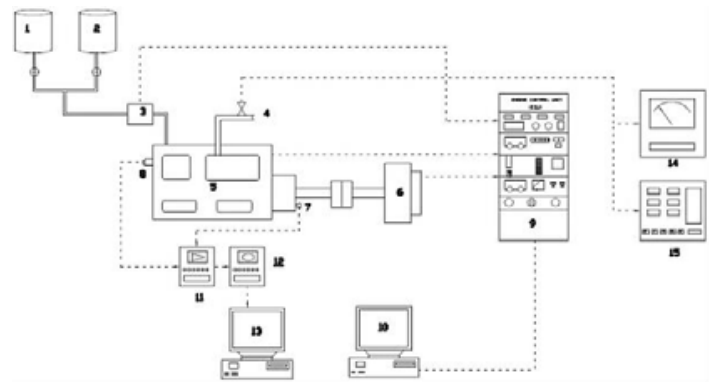

Fig.1. Schematic diagram of engine test bed

1. Diesel tank, 2. Biodiesel tank 3. Fuel flow meter, 4.Engine exhaust, 5.Engine, 6. Eddy current dynamometer, 7. Angle encoder, 8.Pressure transducer, 9.Engine ECU control unit, 10.Engine PC control unit, 11. Signal amplifier, 12. Data acquisition unit, 13.Computer, 14. Control valve, 15. Gas analyzer unit.

\section{Results and discussion}

The effect of biodiesel obtained from a mixture of crude oil diesel blends on engine performance and emissions characteristics were studied for unmodified indirect injection diesel engine.

\subsection{Torque}

The engine torque due to the use of diesel and biodiesel blends at difference engine speed is shown in Fig.2. It is observed that, initially the engine torque increase as speed increases and reached a maximum point before decreased as speed increased. The higher torque achieved by the engine was at $2500 \mathrm{rpm}$ which matted engine maximum torque. At rated engine speed of $2500 \mathrm{rpm}$, torque obtained were $87,86,85.3$, and $85 \mathrm{Nm}$ for neat diesel, $\mathrm{B} 5 \%, \mathrm{~B} 10 \%$, and $\mathrm{B} 20 \%$ respectively. The torque reduction was attributed to the higher viscosity and surface tension of biodiesel during injection process and the back flow across the piston clearance $[9,13]$.

\subsection{Brake specific fuel consumption}

Brake specific fuel consumption for diesel and biodiesel blendsat various engine speed at full load is presented in Fig.3.The BSFC for all tested fuels at lower speed has a tendency to decrease due to higher brake power developmentas a function of load. At lower blends ratio BSFC was found to be 
close to that of diesel. At $20 \%$ blend ratio BSFC was noticed to be higher than that of diesel due to lower heating value. As a result more fuel is needed to obtain same power output $[9,14,15]$.

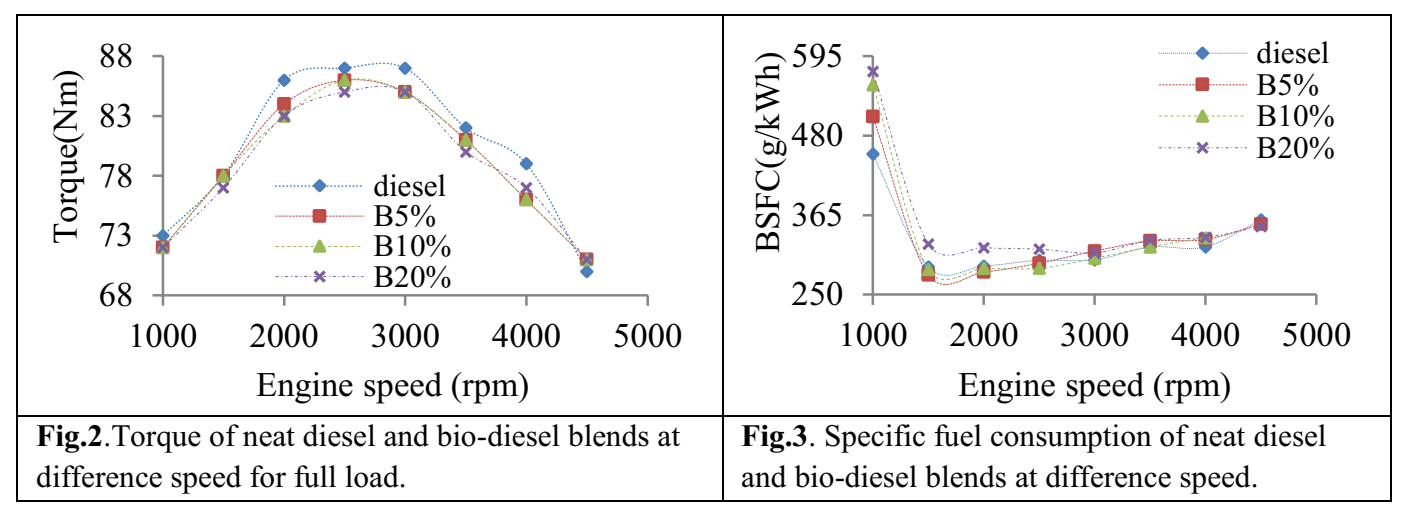

\subsection{Brake thermal efficiency}

The energy content difference of consumed fuel and the power extracted by the engine is defined as BTE, as presented in Fig.4. It is observed that, BTE has the tendency to increase with an increase in engine speed and percentage of biodiesel in the blends due to reduction in heat loss and increased in developed power then reduced as engine speed increased. The maximum BTE obtained are 26.99, $27.58,28.52$ and 26.45 for diesel, $5 \%, 10 \%$ and $20 \%$ blends respectively at the optimum torque of $2500 \mathrm{rpm}$. The engine BTE was improved due to additional lubricity provided by biodiesel and oxygen present which takes part in the combustion process. Similar results were reported by $[9,16]$.

\subsection{Nitrogen oxides emission}

The nitrogen oxide emissions that being emitted from the engine's as a function of speed is presented in Fig.5. It is observed that the NOx emissions emitted by biodiesel blends are slightly higher than that of diesel, particularly as the ratio of biodiesel is higher the blends. This is due to short ignition delay which results in lower temperature during premixed combustion. Similar observation was reported by $[17,18]$ due to lower heating value of biodiesel and increase of air/fuel near stoichiometric condition, resulting higher temperature and higher NOx.

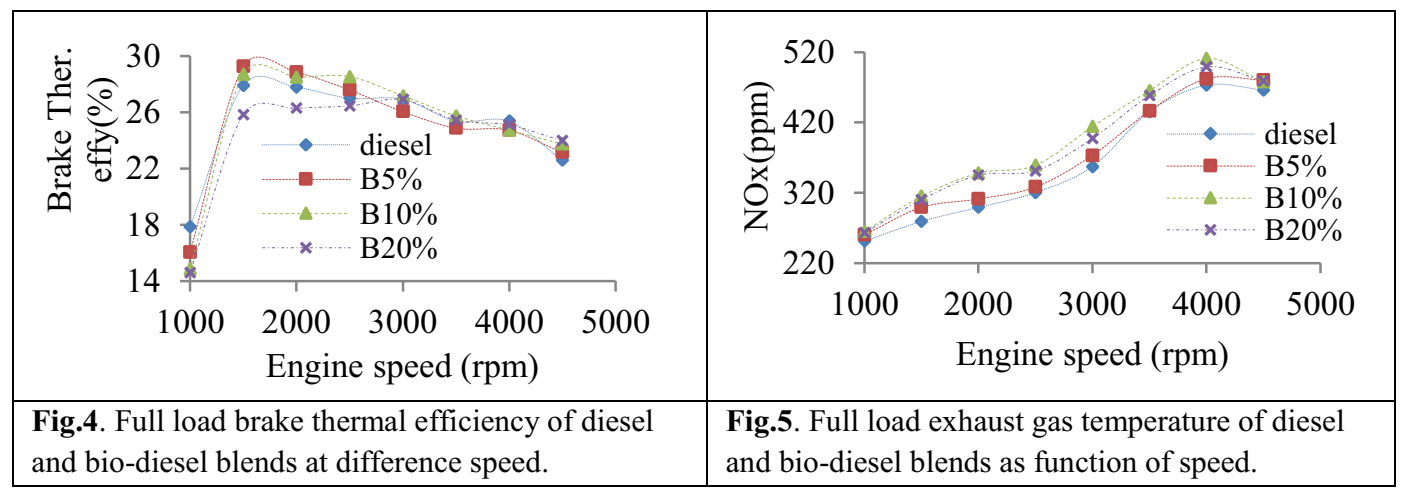

\subsection{Carbon monoxide emission}

Biodiesel emissions are of special concern in relation to meet the environmental standards. Fig.6. shows carbon monoxide emission of diesel and the blends as a function of engine speed. It is observed 
that, $\mathrm{CO}$ emitted by pure diesel is higher compared to biodiesel blends in all case. By increasing biodiesel concentrations in the blends the $\mathrm{CO}$ emission level decreased due to the presence of oxygen that enhanced the combustion. Similar conclusion can found in other authors [19].

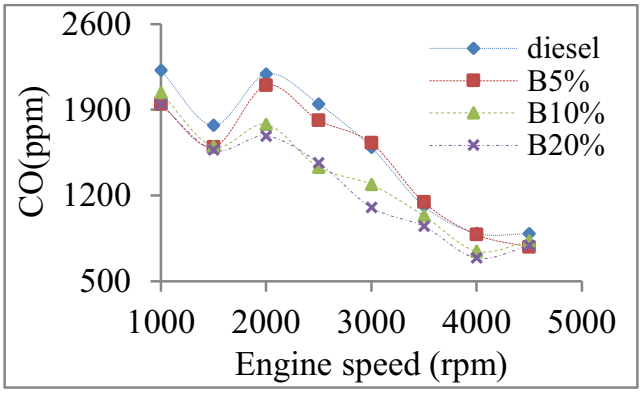

Fig.6.Carbon monoxide emission for diesel and biodiesel blends as function of speed.

\section{Conclusion}

Engine performance and emission characteristics of an IDI diesel engine fuelled biodiesel from a mixture of crude rubber seed oil and crude palm oil diesel blend have been investigated and compared with those of neat diesel. The experimental results confirmed that torque, BSFC, BTE, NOx and CO are a function of biodiesel blends, engine speed and load. For similar operation condition, engine performance decreased as biodiesel concentration increased.

\section{Acknowledgement}

The authors would like to acknowledge Universiti Teknologi PETRONAS for the funding in conducting this research work.

\section{References}

[1] J. Kjärstad and F. Johnsson, Enrg. Policy, 37, (2009)

[2] B. K. Barnwal and M. P. Sharma, Renw. andSust. Enrg. Reviews, 9, (2005)

[3] M. M. Gui, K. T. Ã. Lee, and S. Bhatia, Enrg. J, 33,(2008)

[4] A. E. Atabani, A. S. Silitonga, H. C. Ong, H. H. Masjuki, I. A. Badruddin, and H. Fayaz, Renw. andSust. Enrg. Reviews. J,18, (2013)

[5] A. Demirbas, Appl.Enrg.. J,88,(2011)

[6] D. C. Rakopoulos, C. D. Rakopoulos, E. G. Giakoumis, A. M. Dimaratos, and M. A. Founti, Fuel.J, 90,(2011)

[7] M. Gumus, C. Sayin, and M. Canakci, Fuel. J, 95, (2012)

[8] A. S. Ramadhas, S. Jayaraj, and C. Muraleedharan, Renewable Enrg. J, 30,(2005)

[9] I. K. Reksowardojo, H. N. Bui, R. Sok, A. J. Kilgour, and P. Tirto, Asian Eng. J, (2001)

[10] A. S. Ramadhas, C. Muraleedharan, and S. Jayaraj, Renewable Enrg. J, 30,(2005)

[11] V. E. Geo, G. Nagarajan, and B. Nagalingam, Fuel. J. 89, (2010)

[12] H. Raheman, P. C. Jena, and S. S. Jadav, Enrg. andEnvir. Eng. J, 4,(2013)

[13]B. Gokalp, E. Buyukkaya, and H. S. Soyhan, Biom. andBioenrg. J, 5, (2011)

[14] M. Özkan, Energy and Fuel. J, 11, ( 2007)

[15] A. K. Agarwal and K. Rajamanoharan, Appl. Enrg. J, 86, (2009)

[16] L. Labecki, A. Cairns, J. Xia, A. Megaritis, H. Zhao, and L. C. Ganippa, Appl.enrg. J, 95, (2012)

[17] W. J. Pitz and C. J. Mueller,Prog. Enrg. Combust. Sci. J, 37, (2011)

[18] C. Sayin, M. Gumus, and M. Canakci, Enrg.and Fuel. J, 45, (2010)

[19] D. K. Bora and D. C. Baruah, Renw. And sust. Enrg.Rewiws. J, 16, (2012) 